Article

\title{
Effects of Added Mass and Structural Damping on Dynamic Responses of a 3D Wedge Impacting on Water
}

\author{
Pengyao $\mathrm{Yu}^{1}{ }^{1(1)}$, Muk Chen Ong ${ }^{2, *(1)}$ and Hui $\mathrm{Li}^{3}$ \\ 1 College of Naval Architecture and Ocean Engineering, Dalian Maritime University, Dalian 116026, China; \\ yupengyao@dlmu.edu.cn \\ 2 Department of Mechanical and Structural Engineering and Materials Science, University of Stavanger, \\ Stavanger 4036, Norway \\ 3 College of Shipbuilding Engineering, Harbin Engineering University, Harbin 150001, China; \\ huili@hrbeu.edu.cn \\ * Correspondence: muk.c.ong@uis.no; Tel.: +47-51-831-112
}

Received: 13 March 2018; Accepted: 22 April 2018; Published: 16 May 2018

\begin{abstract}
The impact between the wave and the bottom of a high-speed vessel is often simplified as water-entry problems of wedges. Most investigations focus on the water entry of two dimensional (2D) wedges. The effects of added mass and structural damping are still not fully investigated. By combining the normal mode method, the hydrodynamic impact model of rigid wedges and the potential flow theory, a dynamic model for predicting the response of a three dimensional (3D) wedge impacting on water with a constant velocity is established in this paper. The present model can selectively consider the effects of the added mass and the structural damping. The present method has been validated through comparisons with results of published literatures and commercial software. It is found that the added mass can increase the stress response before the flow separation, and reduce the vibration frequency after the flow separation. Due to the effect of the added mass, the stress response of some positions after the flow separation is even higher than that before the flow separation. The structural damping has a negligible effect on the stress before the flow separation, but it can reduce vibration stress after the flow separation.
\end{abstract}

Keywords: water impact; dynamic response; added mass; structural damping

\section{Introduction}

In rough seas, severe impacts usually occur between waves and the bottom of a high-speed vessel, causing impulsive loads on the hull of the vessel. These hydrodynamic impact loads are characterized by pressures with high peaks and short durations, which may dominate in the design of the hull structure.

The impact problem between the vessel and the waves is often simplified as the impact between a two dimensional (2D) section and static water. As the V-shaped cross-section is a typical section form of the bottoms of high-speed vessels [1], the water entry problem of 2D wedge sections has attracted a great deal of research. Pioneering work can be traced back to von Karman [2] and Wagner [3]. Based on momentum conservation and the concept of added mass, von Karman [2] performed a theoretical investigation of the hydrodynamic loads acting on a wedge. By taking into consideration the local rise of water surface during the water impact, Wagner [3] improved the model proposed by von Karman [2]. Zhao and Faltinsen [4], presenting a nonlinear boundary element method (BEM) for simulating the water entry of 2D sections. Tassin et al. [5] assessed the accuracy of several analytical models for the prediction of hydrodynamic forces and pressure distributions. 
During the water entry of finite width wedges, the jet root may be separated from the surface of the wedge. Tassin et al. [6] investigated the flow separation with analytical separation models. Yu et al. [7] proposed a semi-analytical model considering flow separation and negative pressure correction. This semi-analytical model is verified by comparing with numerical results computed using the commercial finite element code LS-DYNA. Wang et al. [8] presented a two-fluid BEM for the water entry of a free-fall wedge, and the role of the air flow on the closure of the 2D cavity was investigated. Bao et al. [9] developed a BEM model to simulate the free-fall water entry of a wedge with the flow separation. Both vertical and oblique water entries of the wedge were discussed using this method. Kamath et al. [10] investigated the water impact problem of a symmetrical wedge using computational fluid dynamics (CFD) simulations. Their numerical results were in good agreement with the experimental data reported by Yettou et al. [11]. Jalalisendi et al. [12] experimentally characterized the 3D hydrodynamic loading on a rigid wedge by measuring the velocity field on several different planes. Their experimental findings on edge effects were applied to the water entry of 2D elastic wedges in the follow-up study [13].

Since the Wagner theory is convenient to predict the hydrodynamic impact loads, it has been widely used in the water entry of 2D elastic wedges, such as the work of Korobkin et al. [14], Qin and Batra [15], Khabakhpasheva and Korobkin [16] and Datta and Siddiqui [17]. Shams et al. [18] established a semi-analytical model for the water entry of 2D elastic wedges by combining the Euler-Bernoulli beam theory with the potential flow theory. Their method was further extended to water exit problems [19]. With the improvement of numerical methods for the fluid domain, many CFD methods have been applied to solve fluid-structure interaction problems during the water entry of 2D elastic wedges, such as the BEM method [20], the finite volume method (FVM) [21,22], the smoothed particle hydrodynamics (SPH) method $[23,24]$ and the arbitrary Lagrangian-Eulerian (ALE) method $[25,26]$.

Three-dimensional (3D) stiffened plates with several longitudinal stiffeners and transverse frames are typical forms of the ship structure. The bottom segment of a high speed ship can be seen as a 3D wedge composed of stiffened plates. However, studies on the dynamic response of a 3D wedge under the hydrodynamic impact are scarce. Faltinsen [27] performed a coupled analysis between the cross-fluid domain and the 3D wedge. The cross-fluid domain was solved using 2D Wagner theory, and the structure model had to satisfy the orthogonal plate theory. Since the Wagner model was only suitable for impact loads before the flow separation, the vibration response of the wedge after the flow separation was not modelled. Luo et al. [28] performed a decoupled study on the impact response of a 3D wedge which consisted of two stiffened plates. The hydrodynamic impact loads were solved using the 2D matched asymptotic theory, and the structural response was predicted using the finite element method. As structural response was based on the decoupled framework, the effect of the added mass on the vibration response of the wedge was not considered. Luo et al. [29] also performed a coupled study on the dynamic response of a free-fall 3D wedge with the commercial code LS-DYNA. The numerical results were in good agreement with their experimental results. Due to the shallow penetration of the wedge, the vibration response after the flow separation was not presented.

Although the water entry of 2D rigid or elastic wedges has been widely studied, the dynamic response of $3 \mathrm{D}$ wedges subject to the water impact still needs further investigation. The water surrounding the wedge will move together with the wedge during the water entry. However, to the authors' knowledge, the effect of added mass on the dynamic response has not been investigated, especially in the stage after the flow separation. Moreover, most of the previous investigations on the dynamic response of elastic wedges were carried out without considering structural damping. To the authors' knowledge, there is still no reasonable analysis on the effect of the structural damping. Therefore, a dynamic model for the 3D elastic wedge impacting on water with a constant velocity is established in the present study by taking into account the added mass, the structural damping, and the impact loads after the flow separation. Effects of the added mass and the structural damping are investigated. 
The 3D effect of the fluid domain is usually neglected in the studies of the ship slamming $[27,28]$, due to the slender features of the ship structure. This premise is also adopted in the present work and the hydrodynamic loads of the 3D wedge are calculated using the 2D method. This paper is organized as follows. In Section 2, the 2D water entry of the wedge is defined. Section 3 presents the structural dynamic equation based on the normal mode method. In Section 4, the expressions of general forces of 2D wedge sections are derived, including the generalized excitation force and general hydrodynamic coefficients. In Section 5, the dynamic model of the 3D elastic wedge impacting on water with a constant velocity is established. Section 6 presents the results and discussions, including validations of the present model, and investigations of the added mass and the structural damping effects. In Section 7, main conclusions of the present study are summarized. Appendix A presents the derivation of the semi-analytical model reported by Yu et al. [7]. Appendix B shows the modal results of the stiffened plate. Appendix $C$ presents the modal convergence study.

\section{Definition of the 2D Water Entry}

Figure 1 shows the definition sketch of an impact model of a 2D wedge. According to the separation time of the jet root from the wedge surface, the impact process is divided into two stages: the stage before the flow separation and the stage after the flow separation, as shown in Figure 1a,b, respectively. As the wedge discussed in this paper is symmetrical, only half of the wedge is analyzed. As shown in Figure 1a,b, the global coordinate system $o-x y z$ and the local coordinate system $o^{\prime}-\xi \eta \zeta$ are used. The global coordinate system is stationary and its origin is located at the intersection between the symmetry line and the initial water surface. The local coordinate system is fixed to the wedge and its origin is located at the keel of the wedge. The directions of $o x, o z, o \xi$ and $o \zeta$ are shown in Figure $1 \mathrm{a}, \mathrm{b}$. The directions of $o z, o \eta$ are determined by the right-hand rule. $V$ is the constant velocity of the impacting body. The initial state of the water is static. $t$ is the time during the water entry, and $t=0$ means the time instant when the lowest point of the wedge reaches the water surface. $c(t)$ is the half width of the wetted surface. $s(t)$ is the wetted length in the local coordinate system. $\beta$ is the deadrise angle of the wedge. $b$ is the half width of the wedge; $L$ is the length of the wedge surface.

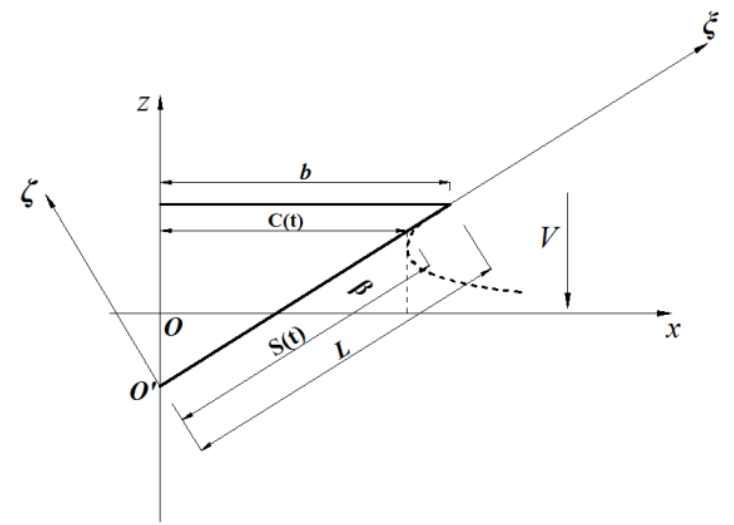

(a)

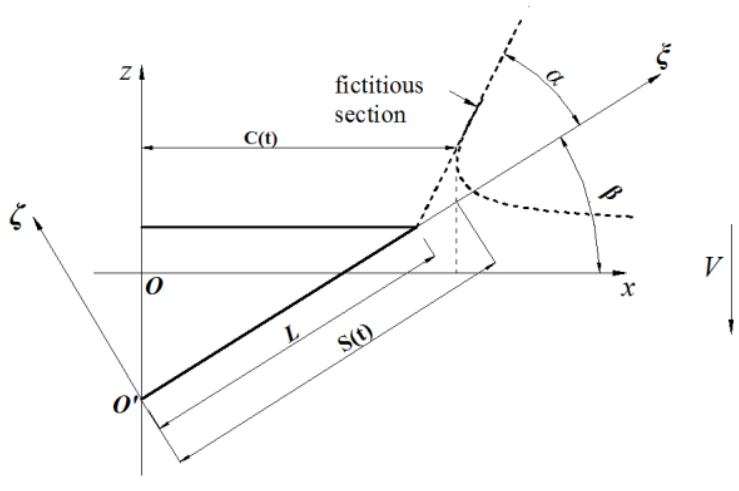

(b)

Figure 1. Impact model of a 2D wedge. (a) Before the flow separation; (b) after the flow separation.

In order to analyze the dynamic response after the flow separation, the semi-analytical hydrodynamic model reported by Yu et al. [7] is adopted in the present study. This model is based on the concept of Fictitious Body Continuation (FBC), which assumes that the water surface rises along the fictitious section after the flow separation. The location of the fictitious section is defined by the angle $\alpha$, as shown in Figure 1b. The detailed explanation of this model is listed in Appendix A. Based on this hydrodynamic model, the impact pressure distribution on the wetted surface can be described as: 


$$
\begin{aligned}
P_{r}(x, t) & =\frac{1}{2} \rho V^{2}\left[\frac{2 \dot{c}(t)}{V} \frac{c(t)}{\sqrt{c^{2}(t)-(\tau x)^{2}}}-\cos ^{2} \beta \frac{c^{2}(t)}{c^{2}(t)-(\tau x)^{2}}-\sin ^{2} \beta\right] \\
\frac{d c}{d t}=\frac{c_{v} V}{\tan \beta} \text { before the flow separation } & \frac{c_{v} V}{d c}=\frac{\left.\cos \theta_{s}\right)+\tan \alpha \cos \theta_{s}}{\tan \beta(1-\operatorname{cter} \text { the flow separation }}
\end{aligned}
$$

where $\tau$ is a parameter introduced to correct the unreasonable negative pressure; $\theta_{s}$ is a parameter that related to the fictitious, and it satisfies the equation $c(t) \cdot \sin \theta_{s}=L \cos \beta ; c_{v}$ is the pile-up coefficient of the fluid surface.

In order to facilitate the calculation of the generalized excitation force, the impact pressure is expressed in the local coordinate system by the transformation $c(t)=s(t) \cdot \cos \beta$ and $x=\xi \cdot \cos \beta$, as shown in the following.

$$
\begin{gathered}
P_{r}(\xi, t)=\rho V \cos \beta \frac{\dot{s}(t) s(t)}{\sqrt{s^{2}(t)-(\tau \xi)^{2}}}-\frac{1}{2} \rho V^{2}\left[\cos ^{2} \beta \frac{s^{2}(t)}{s^{2}(t)-(\tau \xi)^{2}}-\sin ^{2} \beta\right] \\
\frac{d s}{d t}=\frac{c_{v} V}{\sin \beta} \text { before the flow separation } \\
\frac{d s}{d t}=\frac{c_{v} V}{\sin \beta\left(1-\cos \theta_{s}\right)+\cos \beta \tan \alpha \cos \theta_{s}} \text { after the flow separation }
\end{gathered}
$$

It should be noted that the pressure truncation in Equation (A14) is adopted in the present study.

\section{Structural Dynamic Equation}

Based on the finite element theory, the elastic wedge can be decomposed into a system with finite degrees of freedom, and the structural dynamic equation can be expressed as:

$$
[M]\{\ddot{U}\}+[C]\{\dot{U}\}+[K]\{U\}=\{P\}
$$

where $[M]$ is the mass matrix of the structure; $[C]$ is the damping matrix of the structure; $[K]$ is the stiffness matrix of the structure; $\{U\}$ is the nodal displacement array of the structure; $\{P\}$ is the distribution force equivalent nodal array, and the distribution force refers to the impact pressure on the wedge in the present study.

Through the Eigen analysis of the structural dynamic system of Equation (5), modal shapes $\left\{D_{r}\right\}$ of the structure in air (dry modes) can be obtained as follows:

$$
\left\{D_{r}\right\}=\left\{D_{r 1}, D_{r 2}, \cdots D_{r N}\right\}^{T}
$$

where $N$ is the number of nodes for the discrete structure model; $r$ is the order of the vibration mode; $D_{r j}$ is the displacement vector of the $j$-th node in the $r$-th order mode.

In the 3D space coordinate system $o-x y z,\left\{D_{r}\right\}$ can be expressed as

$$
D_{r j}=\left\{u_{r}, v_{r}, w_{r}, \theta_{x r}, \theta_{y r}, \theta_{z r}\right\}_{j}^{T}
$$

where $u_{r}, v_{r}, w_{r}$ are the linear displacement along the $o x, o y$ and $o z$ axes, respectively; $\theta_{x r}, \theta_{y r}, \theta_{z r}$ are the angular displacement around the $o x, o y$ and $o z$ axes, respectively.

The modal number of elastic structures is actually infinite, and several lower order modes usually represent the primary contribution to structural responses. When $m$ modes are selected, the displacement shapes of the discrete node system can be expressed as: 


$$
[D]=\left[\left\{D_{1}\right\},\left\{D_{2}\right\}, \cdots,\left\{D_{m}\right\}\right]
$$

By using the normal mode method, the node displacement of the system under the impact load can be expressed as:

$$
\{U\}=[D]\{p\}=\sum_{r=1}^{m}\left\{D_{r}\right\} p_{r}(t)
$$

where $\{p\}$ is the principal coordinate array; $p_{r}(t)$ represents the contribution of the $r$-th mode to the structural response.

Substituting Equation (9) into Equation (5) and multiplying the two sides by $[D]^{T}$, the principal coordinate equation of the structural system can be achieved:

$$
[a]\{\ddot{p}\}+[b]\{\dot{p}\}+[c]\{p\}=\{Z\}
$$

where $[a]$ is the generalized mass matrix of the structure, $[a]=[D]^{T}[M][D] ;[b]$ is the generalized damping matrix of the structure, $[b]=[D]^{T}[C][D] ;[c]$ is the generalized stiffness matrix of the structure $[c]=[D]^{T}[K][D] ;[Z]$ is the generalized distribution force matrix, $[Z]=[D]^{T}\{P\}$.

The generalized damping matrix of the structure is usually determined by experiments or experience. In the normal mode method, it is assumed diagonal such that $b_{r r}=2 \omega_{r} v_{r} a_{r r}$, where $\omega_{r}$ is the natural frequency and $v_{r}$ is the structural damping factor. The effect of structural damping is investigated by changing the structural damping factor in the following study.

Thus, the structural dynamic equation, which takes the nodal displacement as an unknown variable, has been transformed into the structural dynamic equation with the principal coordinate as the unknown variable. After the computation of the generalized distribution force, the principal coordinate corresponding to each mode can be solved, and the structural response can be solved using the normal mode method.

\section{Generalized Impact Forces of 2D Sections}

With reference to the work of Faltinsen [27], the generalized force acting on the 3D wedge can be achieved by the integration of generalized forces of $2 \mathrm{D}$ wedge sections. The hydrodynamic impact loads on wedges can be divided into two parts. One is the excitation force corresponding to the overall impact velocity of the wedge; this part is calculated using the hydrodynamic impact model of rigid wedges. The other is the hydrodynamic force representing the effect of the added mass on the elastic vibration of the wedge, which is expressed as hydrodynamic coefficients in the dynamic equation; this part is calculated using the potential flow theory. The two parts of generalized forces on $2 \mathrm{D}$ wedge sections are derived in Sections 4.1 and 4.2, respectively.

\subsection{Generalized Excitation Force}

The outer shell deformation of the 3D elastic wedge can be seen as the deformation of a series of $2 \mathrm{D}$ wedge sections which are parallel to each other. Using the normal mode of the 3D wedge, the modal displacement of 2D sections can be achieved. Considering the impact pressure acting in the normal direction of the wedge, the displacement mode of the 2D section in the normal direction is defined as $\psi_{i}^{k}(\xi)$, where $i$ represents the $i$-th order mode and $k$ represents the $k$-th 2D section of the 3D wedge. Combing the displacement mode of the $2 \mathrm{D}$ section with the pressure distribution based on the semi-analytical model, the generalized excitation force of the 2D section can be expressed as:

$$
f_{\text {exc }, i}\left(s^{k}(t)\right)=\int_{0}^{s^{k}(t)} P_{r}(\xi, t) \cdot \psi_{i}^{k}(\xi) d \xi \text { before the flow separation }
$$




$$
f_{\text {exc,i }}\left(s^{k}(t)\right)=\int_{0}^{L} P_{r}(\xi, t) \cdot \psi_{i}^{k}(\xi) d \xi \text { after the flow separation }
$$

where $f_{\text {exc, } i}\left(s^{k}(t)\right)$ is the generalized excitation force of the $k$-th section; $s^{k}(t)$ is the wetted length of the $k$-th section at the $t$ moment in the local coordinate system.

\subsection{General Hydrodynamic Coefficients}

Incompressible flow and the potential flow theory are adopted in the present study. According to Faltinsen [27] and the simplified method in Stenius [26], the velocity potential before the flow separation caused by the elastic vibration of the wedge is:

$$
\varphi(\xi, t)=\overline{\dot{w}}(s(t)) \cdot \sqrt{s^{2}(t)-\xi^{2}}
$$

where $\overline{\dot{w}}$ is the mean deflection velocity in the normal direction of the wedge surface.

Based on the linear Bernoulli equation, the impact pressure over the wetted surface representing the effect of the added mass can be achieved:

$$
\begin{aligned}
& P_{e}(\xi, t)=-\rho \frac{\partial \varphi}{\partial t} \\
& P(\xi, t)=-\rho \tilde{\ddot{w}}(s(t)) \cdot \sqrt{s^{2}(t)-\xi^{2}}-\rho \overline{\dot{w}}(s(t)) \cdot \frac{s(t)}{\sqrt{s^{2}(t)-\xi^{2}}} \cdot \frac{d s}{d t}
\end{aligned}
$$

For the $k$-th 2D section of the 3D wedge $s^{k}(t)$, the generalized hydrodynamic force $f_{\text {ela }, i}\left(s^{k}(t)\right)$ representing the effect of the added mass can be written as:

$$
f_{e l a, i}\left(s^{k}(t)\right)=\int_{0}^{s^{k}(t)} P_{e}(\xi, t) \cdot \psi_{i}^{k}(\xi) d \xi
$$

Substituting Equation (13) into Equation (14), then

$$
f_{\text {ela }, i}\left(s^{k}(t)\right)=\int_{0}^{s^{k}(t)}\left[-\rho \overline{\ddot{w}} \cdot \sqrt{\left(s^{k}(t)\right)^{2}-\xi^{2}}-\rho \overline{\dot{w}} \cdot \frac{s^{k}(t)}{\sqrt{\left(s^{k}(t)\right)^{2}-(\tau \xi)^{2}}} \cdot \dot{s}^{k}(t)\right] \cdot \psi_{i}^{k}(\xi) d \xi
$$

In Equation (15), it can be seen that $f_{\text {ela,i }}\left(s^{k}(t)\right)$ is related to the mean deflection velocity $\overline{\dot{w}}$ and acceleration $\overline{\ddot{w}}$ in the normal direction of the wedge surface. By defining $p_{j}(t)$ as the $j$-th order principal coordinate of the $3 \mathrm{D}$ elastic wedge, the mean displacement, velocity and acceleration can be obtained as:

$$
\begin{aligned}
& \bar{w}\left(s^{k}(t)\right)=\sum_{j=1}^{m} \bar{\psi}_{j}\left(s^{k}(t)\right) \cdot p_{j}(t) \\
& \overline{\dot{w}}\left(s^{k}(t)\right)=\sum_{j=1}^{m} \bar{\psi}_{j}\left(s^{k}(t)\right) \cdot \dot{p}_{j}(t) \\
& \overline{\ddot{w}}\left(s^{k}(t)\right)=\sum_{j=1}^{m} \bar{\psi}_{j}\left(s^{k}(t)\right) \cdot \ddot{p}_{j}(t)
\end{aligned}
$$

where $m$ is the number of modes used in the calculation; $\dot{p}_{j}(t)$ is the first order derivative of $p_{j}(t)$; $\ddot{p}_{j}(t)$ is the second order derivative of $p_{j}(t) ; \bar{\psi}_{j}\left(s^{k}(t)\right)$ is the mean deflection of the wetted area.

$$
\bar{\psi}_{j}\left(s^{k}(t)\right)=\int_{0}^{s^{k}(t)} \frac{\psi_{j}(\xi)}{s^{k}(t)} d \xi
$$


By substituting Equations (16b) and (16c) into Equation (15), $f_{e l a, i}\left(s^{k}(t)\right)$ can be expressed as follows:

$$
\begin{gathered}
f_{\text {ela }, i}\left(s^{k}(t)\right)=-\sum_{j=1}^{m} A_{i j}^{k}\left(s^{k}(t)\right) \cdot \ddot{p}_{j}(t)-\sum_{j=1}^{m} B_{i j}^{k}\left(s^{k}(t)\right) \cdot \dot{p}_{j}(t) \\
A_{i j}^{k}\left(s^{k}(t)\right)=\int_{0}^{s^{k}(t)} \rho \bar{\psi}_{j}\left(s^{k}(t)\right) \cdot \sqrt{\left(s^{k}(t)\right)^{2}-\xi^{2}} \cdot \psi_{i}^{k}(\xi) d \xi \\
\left.\left.B_{i j}^{k}\left(s^{k}(t)\right)=\int_{0}^{s^{k}(t)}-\rho V \cos \beta \bar{\psi}_{j}\left(s^{k}(t)\right) \cdot \frac{s^{k}(t)}{\sqrt{\left(s^{k}(t)\right)^{2}-(\tau \xi)} \cdot\left(\frac{\left(s^{k}(t)\right)^{2}}{\left(s^{k}(t)\right)^{2}-(\tau \xi)}-\dot{s}^{k}(t)\right.}-\tan ^{2} \beta\right)\right] \cdot \psi_{i}^{k}(\xi) d \xi
\end{gathered}
$$

where $i, j$ are order numbers of modes; $A_{i j}^{k}\left(s^{k}(t)\right), B_{i j}^{k}\left(s^{k}(t)\right)$ are the generalized hydrodynamic coefficients of the $k$-th section.

For the stage after the flow separation, the above derivation is assumed to be valid and this assumption will be verified in Section 6.3. Considering that the upper limit of the integration should not beyond the actual wedge surface, generalized hydrodynamic coefficients after the flow separation should be expressed as

$$
\begin{gathered}
A_{i j}^{k}\left(s^{k}(t)\right)=\int_{0}^{L} \rho \bar{\psi}_{j}\left(s^{k}(t)\right) \cdot \sqrt{\left(s^{k}(t)\right)^{2}-\xi^{2}} \cdot \psi_{i}^{k}(\xi) d \xi \\
B_{i j}^{k}\left(s^{k}(t)\right)=\int_{0}^{L}-\rho V \cos \beta \bar{\psi}_{j}\left(s^{k}(t)\right) \cdot \frac{s^{k}(t)}{\left.\sqrt{\left(s^{k}(t)\right)^{2}-(\tau \xi)} \cdot\left(\frac{\left(s^{k}(t)\right)^{2}}{\left(s^{k}(t)\right)^{2}-(\tau \xi)^{2}}-\operatorname{san}^{2} \beta\right)\right] \cdot \psi_{i}^{k}(\xi) d \xi}
\end{gathered}
$$

The generalized hydrodynamic force representing the effect of the added mass has been expressed with generalized hydrodynamic coefficients and principal coordinates.

\section{Dynamic Equation of the 3D Wedge}

By combining the generalized excitation force and general hydrodynamic coefficients illustrated above, the total generalized impact forces of a $2 \mathrm{D}$ section $f_{i}\left(s^{k}(t)\right)$ is obtained as:

$$
f_{i}\left(s^{k}(t)\right)=f_{\text {exc,i }}\left(s^{k}(t)\right)+f_{\text {ela }, i}\left(s^{k}(t)\right)
$$

Integrating the generalized force of different 2D sections by using the trapezoidal method, the generalized force of the 3D wedge can be expressed in the following equation:

$$
F_{i}(t)=\sum_{k=1}^{n-1} 0.5 \times\left[f_{i}\left(s^{k}(t)\right)+f_{i}\left(s^{k+1}(t)\right)\right] \cdot d_{k}
$$

where $F_{i}(t)$ is the $i$-th order general force of the 3D wedge; $n$ is the number of 2D sections; $s^{k}(t)$ and $s^{k+1}(t)$ are two adjacent sections; $d_{k}$ is the distance between $s^{k}(t)$ and $s^{k+1}(t)$.

By defining $A_{i j}(t), B_{i j}(t)$ and $F_{e x c, i}(t)$ :

$$
\begin{aligned}
& A_{i j}(t)=\sum_{k=1}^{n-1} 0.5 \times\left[A_{i j}^{k}\left(s^{k}(t)\right)+A_{i j}^{k}\left(s^{k+1}(t)\right)\right] \cdot d_{k} \\
& B_{i j}(t)=\sum_{k=1}^{n-1} 0.5 \times\left[B_{i j}^{k}\left(s^{k}(t)\right)+B_{i j}^{k}\left(s^{k+1}(t)\right)\right] \cdot d_{k}
\end{aligned}
$$




$$
F_{\text {exc }, i}(t)=\sum_{k=1}^{n-1} 0.5 \times\left[f_{\text {exc }, i}\left(s^{k}(t)\right)+f_{\text {exc }, i}\left(s^{k+1}(t)\right)\right] \cdot d_{k}
$$

the generalized force of the 3D wedge can be expressed as:

$$
F_{i}(t)=-\sum_{j=1}^{m} A_{i j}(t) \cdot \ddot{p}_{j}(t)-\sum_{j=1}^{m} B_{i j}(t) \cdot \dot{p}_{j}(t)+F_{e x c, i}(t)
$$

By substituting Equation (23) into Equation (10), the dynamic equation of the 3D wedge is written as:

$$
\{[a]+[A]\}\{\ddot{p}\}+\{[b]+[B]\}\{\dot{p}\}+[c]\{p\}=\left\{F_{\text {exc }}\right\}
$$

Here $\{q\}=\{\dot{p}\}$ is introduced to transform the second order differential equations into the first order differential equations.

$$
\left[\begin{array}{c}
\{\dot{p}\} \\
\{\dot{q}\}
\end{array}\right]=\left[\begin{array}{c}
\{q\} \\
\frac{\left[F_{e x c}\right]-\{[b]+[B]\}\{q\}-[c]\{p\}}{[a]+[A]}
\end{array}\right]
$$

During the water entry of the wedge, Equations (4a) or (4b) also needs to be solved. Thus, it is necessary to solve $(2 m+1)$ first-order differential equations. Equations $(4 a)$ or $(4 b)$ and $(25)$ are solved using a Runge-Kutta 4th-order scheme. The matrices $\left[F_{\text {exc }}\right],[A],[B], \bar{\psi}_{j}\left(s^{k}(t)\right)$ are updated in each step. The initial conditions are $\{q\}=\{p\}=\{0\}, s^{k}(t)=0$.

\section{Results and Discussions}

In this section, the constant-velocity impact of a 3D wedge is investigated by using the present dynamic model. The wedge model is derived based on the V-shaped bottom of a high speed ship. Firstly, geometric parameters and the finite element model of the wedge are described. Secondly, the present model is validated by comparing the present predictions with results of published literatures and the commercial software. Lastly, the effects of the added mass and the structural damping on the dynamic response of the 3D wedge are investigated.

\subsection{Description of the Wedge}

The cross section of the 3D wedge is shown in Figure 2. The wedge is symmetry and contains two same stiffened plates. As shown in Figure 3, 7 longitudinal bulb stiffeners and 2 T-shape transverse frames are arranged at equal intervals in the stiffened plate. The bulb stiffener is converted into an equivalent L-shape stiffener in the finite element analysis. For the L-shape stiffener and the T-shape transverse frame, " $\mathrm{tw}$ " is the thickness of the web plate, "hw" is the height of the web plate, " $\mathrm{tf}$ " is the thickness of the face plate, "bf" is the breadth of the face plate. Structural parameters of the stiffened plate are listed in Table 1. The locations for the analysis of structural stress responses are presented in Figure 3. S1-S3 and S7-S9 are located at the face plate of the longitudinal stiffeners. S4-S6 are located at the face plate of the transverse frames.

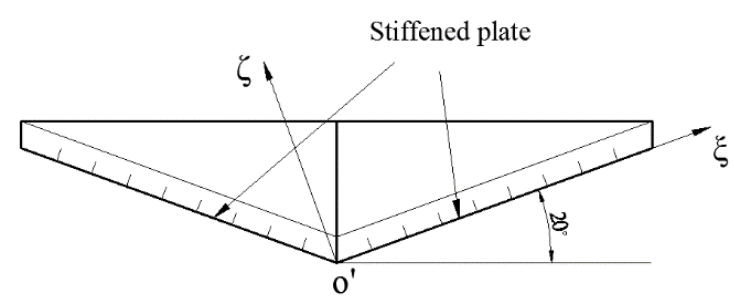

Figure 2. The cross section of the $3 \mathrm{D}$ wedge. 


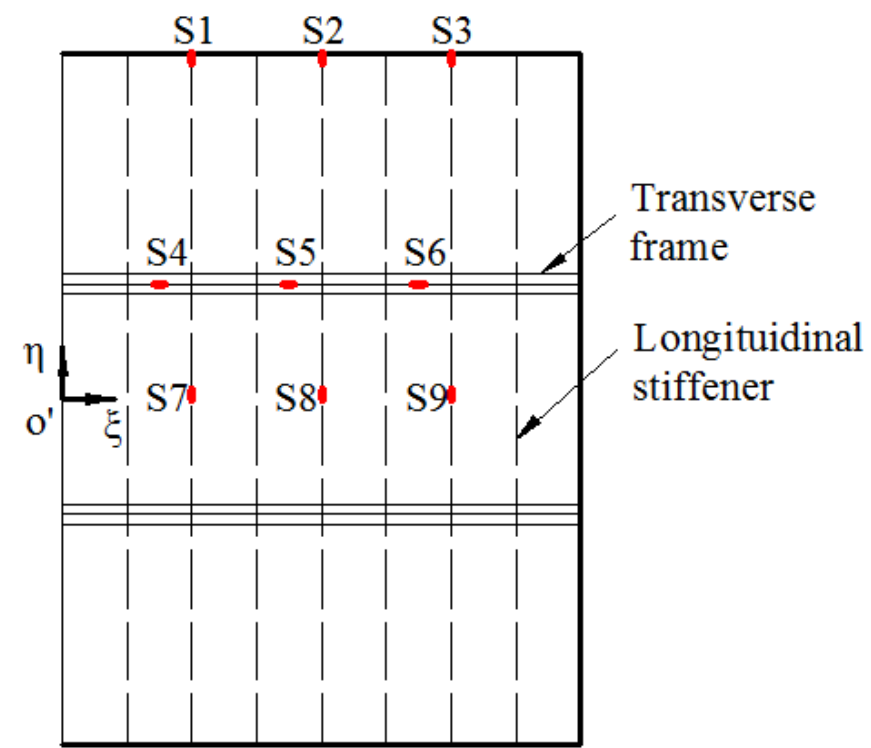

Figure 3. One side of the 3D wedge.

Table 1. Structural parameters of the stiffened plate.

\begin{tabular}{cccc}
\hline Particulars & Value & Unit \\
\hline Density & 7850 & $\mathrm{~kg} / \mathrm{m}^{3}$ \\
Modulus of elasticity & & $2.07 \times 10^{11}$ & $\mathrm{pa}$ \\
Poisson ratio & 0.3 & - \\
Thickness of the plate & 12 & $\mathrm{~mm}$ \\
Distance between longitudinal stiffeners & 675 & $\mathrm{~mm}$ \\
\hline Dimensions of longitudinal stiffeners & $\mathrm{hw}$ & 9 & $\mathrm{~mm}$ \\
& $\mathrm{tf}$ & 200 & $\mathrm{~mm}$ \\
& $\mathrm{bf}$ & 19.7 & $\mathrm{~mm}$ \\
\hline Distance between transverse frames & & 39.8 & $\mathrm{~mm}$ \\
\hline & $\mathrm{tw}$ & 2400 & $\mathrm{~mm}$ \\
\hline Dimensions of transverse frames & $\mathrm{hw}$ & 400 & $\mathrm{~mm}$ \\
& $\mathrm{tf}$ & 16 & $\mathrm{~mm}$ \\
& $\mathrm{bf}$ & 200 & $\mathrm{~mm}$ \\
& & & $\mathrm{~mm}$ \\
\hline
\end{tabular}

The geometric model is meshed by referring to the finite element model in the work of Luo et al. [28]. The spacing of longitudinal stiffeners is divided into 10 parts. The spacing of transverse frames is divided into 20 parts. The web plate of the longitudinal stiffener contains 4 elements in its height. The face plate of the longitudinal stiffener contains 1 element in its width. The web plate of the transverse frame contains 8 elements in its height. The face plate of the transverse frame contains 4 elements in its width. The local coordinate system $o^{\prime}-\xi \eta \zeta$ which is fixed to the stiffened plate is shown in Figure 3. $o^{\prime} \zeta$ can be determined using the right-hand rule. As the stiffened plate is symmetrical about the plane $o^{\prime}-\xi \zeta$, only half of the stiffened plate needs to be analyzed. The symmetry boundary $\theta_{\xi}=U_{\eta}=\theta_{\zeta}=0$ is applied to nodes in the symmetry plane $o^{\prime}-\xi \zeta$ and the supported boundary $U_{\xi}=U_{\eta}=U_{\zeta}=0$ is applied to nodes in the other three sides, as shown in Figure 4 . As there are 30 elements in the direction of the $o^{\prime}-\eta$ axis, the number of 2D sections in the Equation (21) is set as $n=31$. 


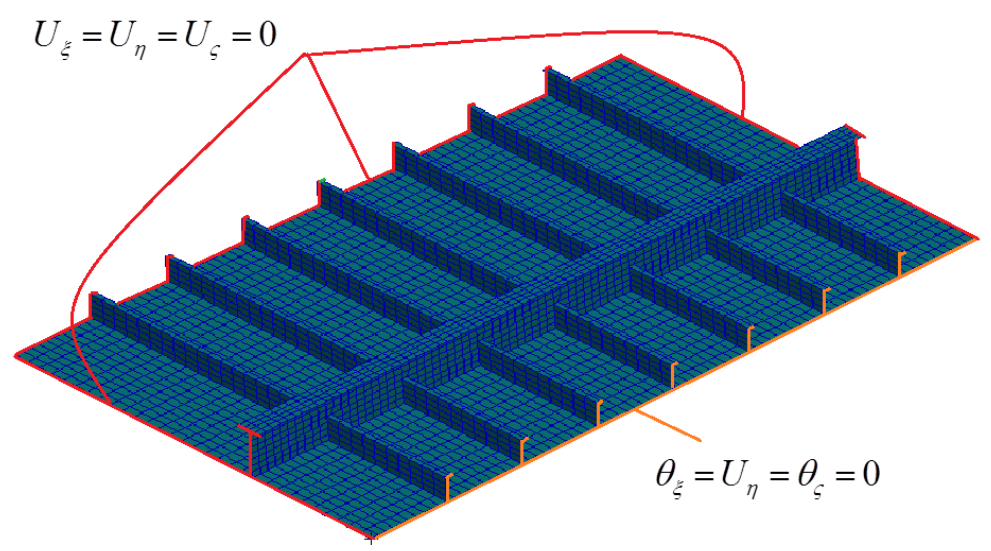

Figure 4. Boundary conditions of the stiffened panel.

\subsection{Validation of the Present Method}

As there are limited studies on the water entry of 3D wedges, verification data for the impact of a 3D elastic wedge with a constant velocity has not yet been found. Hence, the present method is first validated by comparing the present numerical predictions with the results of $2 \mathrm{D}$ rigid and elastic wedges reported by published literature. Then, the applicability of the present method to 3D wedges is validated by comparing the present numerical predictions with results obtained from the commercial software.

\subsubsection{Comparison with Published Literature}

Figure 5 shows the comparison of the pressure distribution with different deadrise angles before the flow separation. The similarity solution was reported by Zhao and Faltinsen [4]. It can be seen that the results of the present method generally agree well with those of the similarity solution, even though some deviations appear in the result with the $20^{\circ}$ deadrise angle. Figure 6 shows the comparison of the impact forces in the stages before and after the flow separation, where $F_{Z}$ is the vertical impact force of the half wedge. The methods adopted by Maki et al. [21] and Yu et al. [7] were the FVM in OpenFOAM (version 1.5) and the ALE in LS-DYNA, respectively. It can be seen that results of the present method agree well with those of the published data.

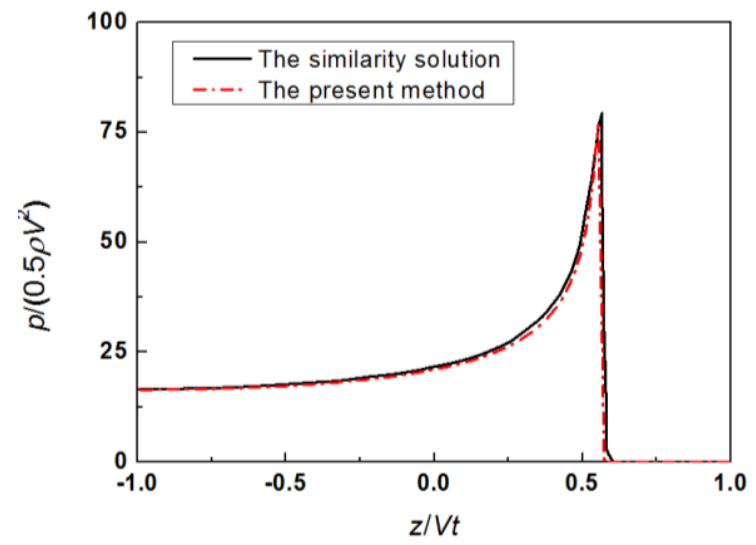

(a)

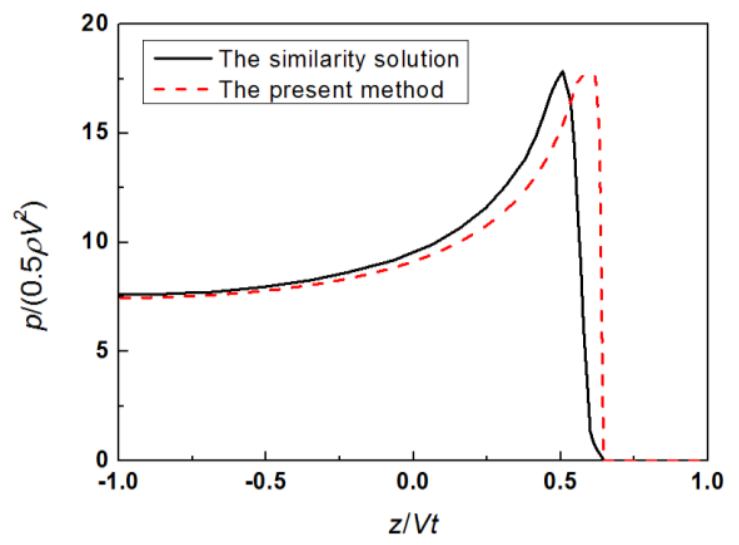

(b)

Figure 5. Comparison of the pressure distribution before the flow separation. (a) $10^{\circ}$ deadrise angle; (b) $20^{\circ}$ deadrise angle. 


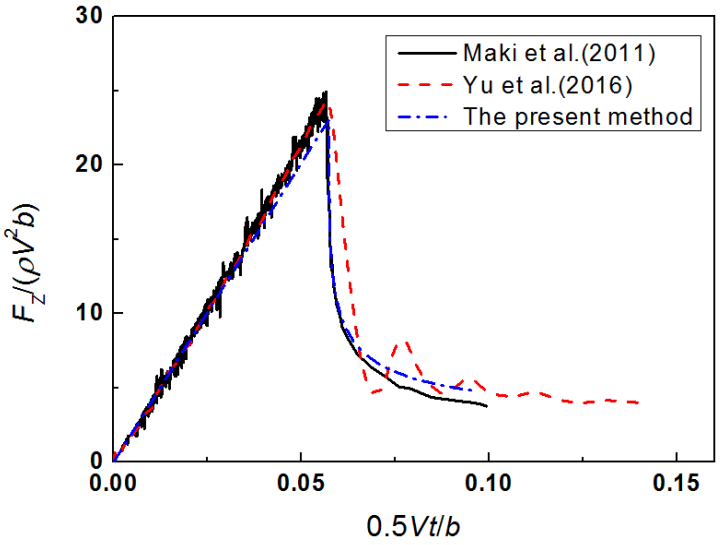

(a)

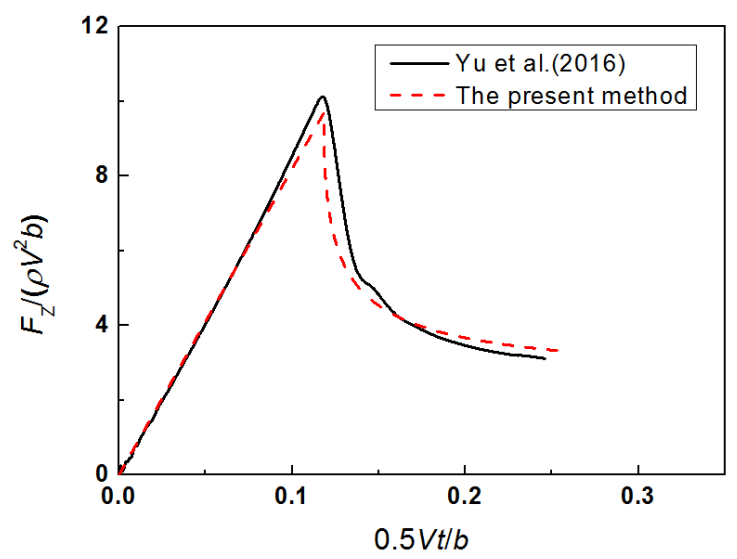

(b)

Figure 6. Comparison of the impact force in the stages before and after the flow separation. (a) $10^{\circ}$ deadrise angle; (b) $20^{\circ}$ deadrise angle.

The present method is applied to the water entry of 2D elastic wedges with the consideration of the added mass. Figure 7 shows the comparison of the time-history deflection result at the center of the length $L$ between the present numerical predictions and the published results reported by Piro and Maki [22]. The fluid domain in Piro and Maki [22] was solved by using the CFD open source code OpenFOAM. It can be seen that results of two methods not only agree well before the flow separation, but also after. The agreement of the vibration response after the flow separation also proves that the previous assumption in the calculation of the generalized hydrodynamic coefficients after the flow separation is physically sound.

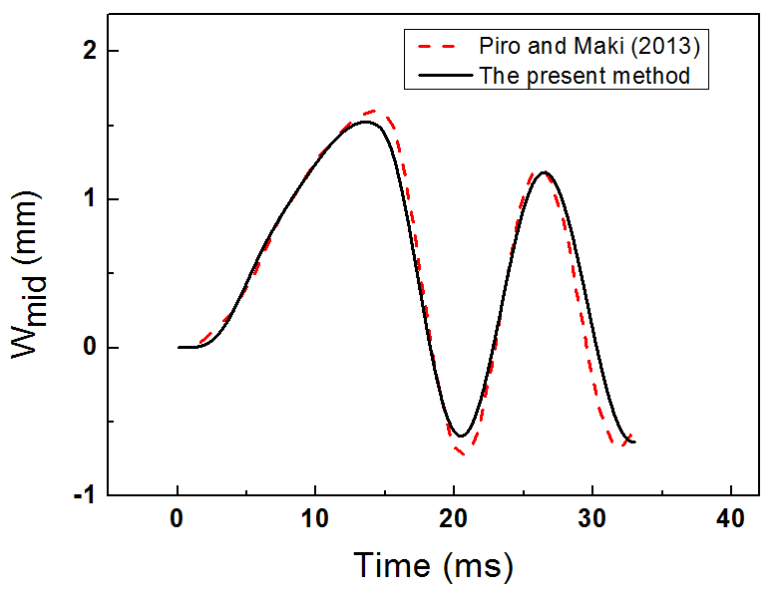

Figure 7. Comparison of the time-history deflection results at the center of the length $L$.

\subsubsection{Comparison with the Commercial Software}

The present method can selectively consider the effect of the added mass and the structural damping. When $[A]=[B]=[b]=0$, the generalized hydrodynamic coefficients and the generalized structural damping matrix are ignored in the dynamic equation. Regardless of whether the generalized hydrodynamic coefficients and the generalized structural damping matrix are considered or not, the numerical scheme of the present model is the same. With reference to the work of Luo et al. [28], the commercial finite element software can calculate structural responses under the condition without considering the added mass and the structural damping. In order to validate the numerical scheme of the present model, results of the present model and the commercial software LS-DYNA are 
compared. Results of the commercial software refer to the impact pressure that is computed by using the semi-analytical model of rigid wedges mentioned above; the dynamic response is solved using LS-DYNA.

Through the modal analysis in Appendix B and the modal convergence study in Appendix C, it is considered that the first 50 modes are sufficient to calculate the structural response of the present stiffened plate. Figure 8 shows the comparison between results of the present model and the commercial software LS-DYNA. The impact velocity of the wedge is assumed to be a constant velocity $6 \mathrm{~m} / \mathrm{s}$ in the present study, which is the impact velocity that the designer expects the stiffened plate to withstand according to the rule for the design of ship structures [30]. It can be seen that the results of the two methods are in good agreement, which not only includes the impact stage before the flow separation, but also the vibration stage after the flow separation. Some slight discrepancies between the two methods may be caused by different algorithms for solving structural dynamics equations. The present model in this paper is solved using the normal mode method, while the software LS-DYNA is based on the explicit finite element method. In general, the numerical scheme of the present model is suitable for the prediction of the impact response of the 3D elastic wedge.

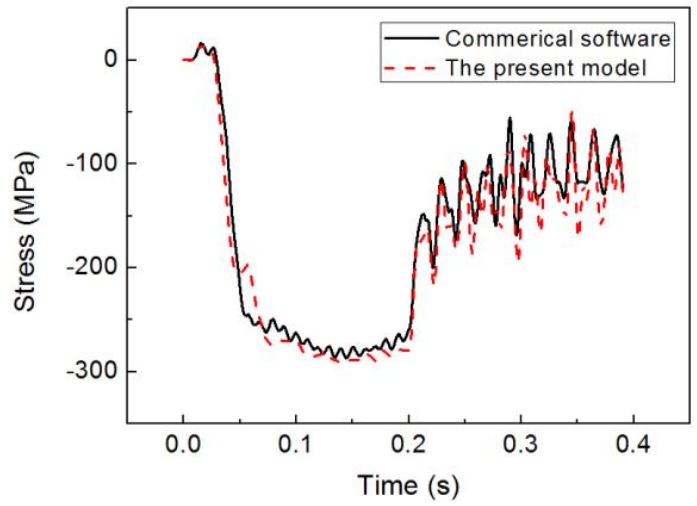

(a)

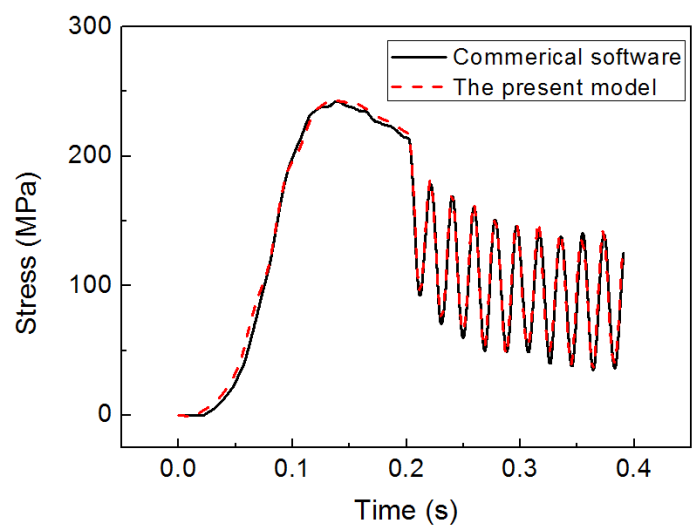

(c)

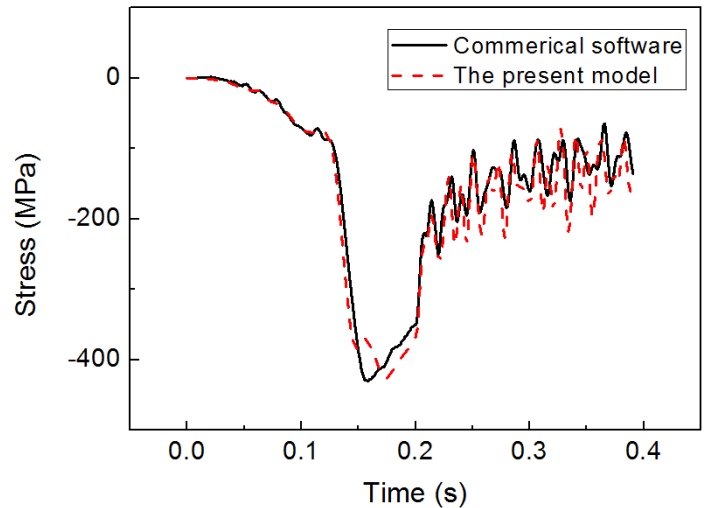

(b)

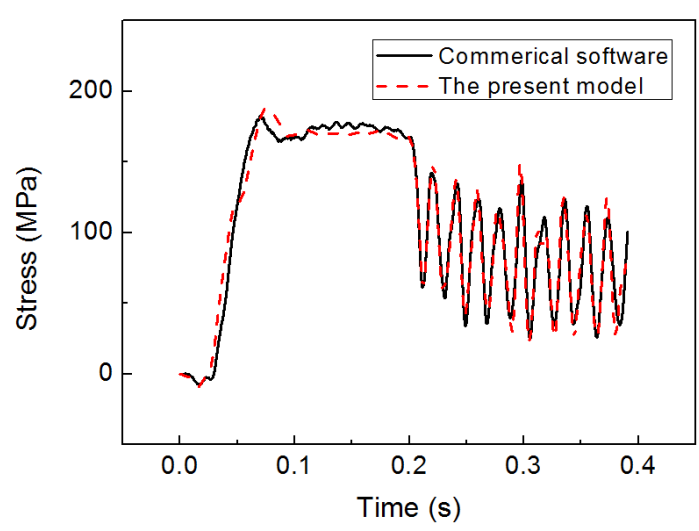

(d)

Figure 8. Comparison between results of the present model and the commercial software. (a) S1; (b) S3; (c) S5; (d) S7. S1-S7 represent the locations on the stiffened plate for the analysis of structural stress responses.

\subsection{Effect of the Added Mass}

In order to discuss the effect of the added mass, a comparative analysis on the dynamic response of the 3D elastic wedge has been carried out. The impact velocity is constantly set as $6 \mathrm{~m} / \mathrm{s}$ and the structural damping is not considered. Through Equation (4a), the starting time of the flow separation with the impact velocity $6 \mathrm{~m} / \mathrm{s}$ is about $0.19 \mathrm{~s}$. Figure 9 shows that the overall trends of stress responses 
before the flow separation are the similar. The peak value of the method with the added mass is higher than that without the added mass. The vibration response of the two methods shows significant discrepancies after the flow separation. The vibration frequency of the method with the added mass is lower than that without the added mass. For the position S7, the stress response after the flow separation is even higher than that before the flow separation, due to the effect of the added mass.

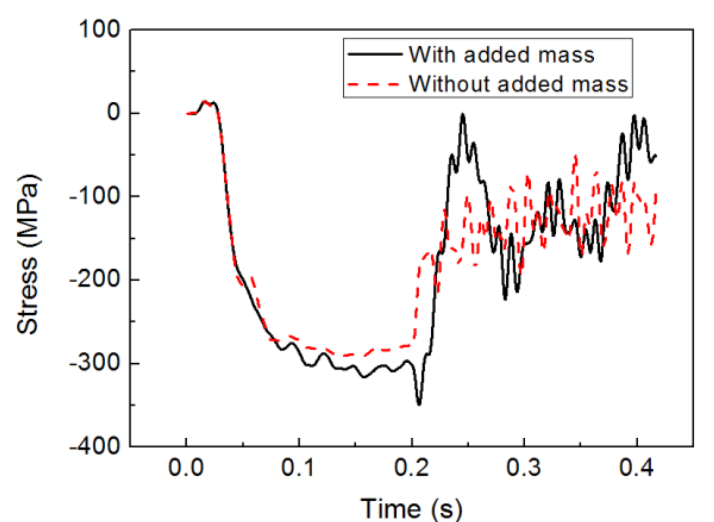

(a)

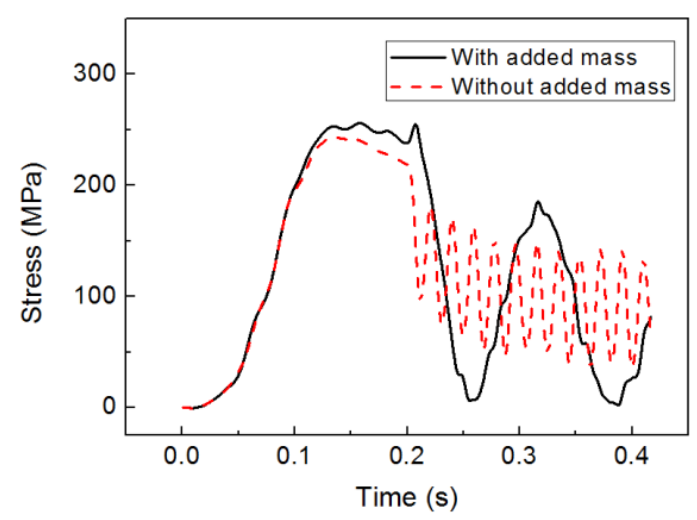

(c)

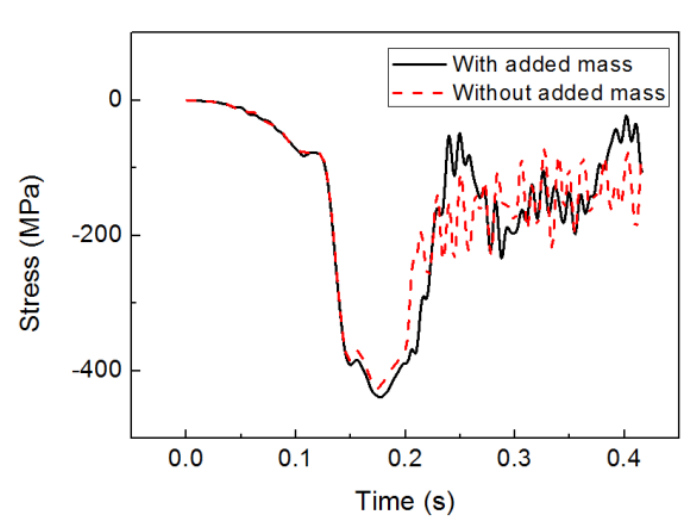

(b)

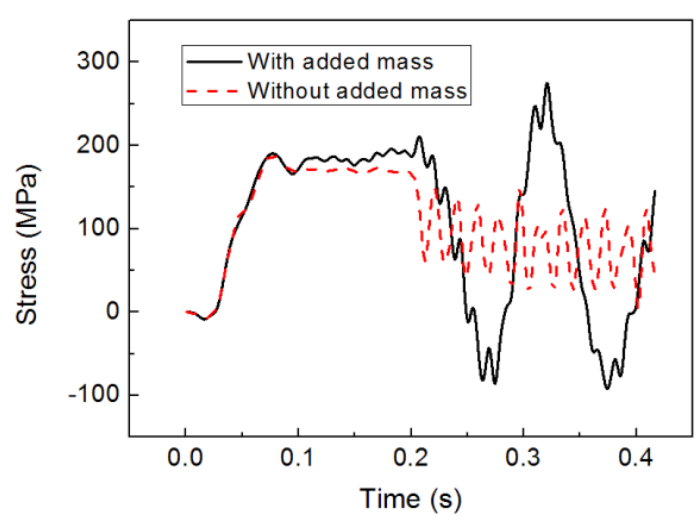

(d)

Figure 9. Comparative analysis on the effect of the added mass. (a) S1; (b) S3; (c) S5; (d) S7.

Figure 10 shows the fast Fourier transform (FFT) results of the stress responses without the added mass. The FFT is not conducted on the stress responses with the added mass, which is due to that the oscillating cycles included in the stress responses with the added mass are scarce. It can be seen that the FFT results of the stress responses without the added mass have a peak value near the first dry modal frequency, which indicates that the first order mode plays an important role in the vibration response after the flow separation.

Table 2 shows the comparison of peak values of absolute stresses. For the position S7, the peak stress of the method with the added mass is about $45.76 \%$ higher than that without the added mass, due to that the peak stress of the method with the added mass appears in the stage after the flow separation.

\subsection{Effect of the Structural Damping}

Figure 11 shows the comparative analysis on the effect of the structural damping. The impact velocity is constantly set as $6 \mathrm{~m} / \mathrm{s}$ and five different structural damping factors (i.e., $\mathrm{Vr}=0,0.005,0.02$, 0.1 and 0.5 ) are considered. It can be seen that the structural damping has negligible effect on the stress before the flow separation, and it reduces vibration stress after the flow separation. Referring to the 
work of $\mathrm{Wu}$ and Moan [31], the structural damping factor of the ship steel is around 0.01, which may be as low as 0.005 and as high as 0.02 . It can be seen that the effect of the structural damping is not obvious in this range, and only a small amount of high frequency oscillation stress is suppressed after flow separation. Therefore, it is reasonable for the steel structure to neglect the effect of the structural damping.

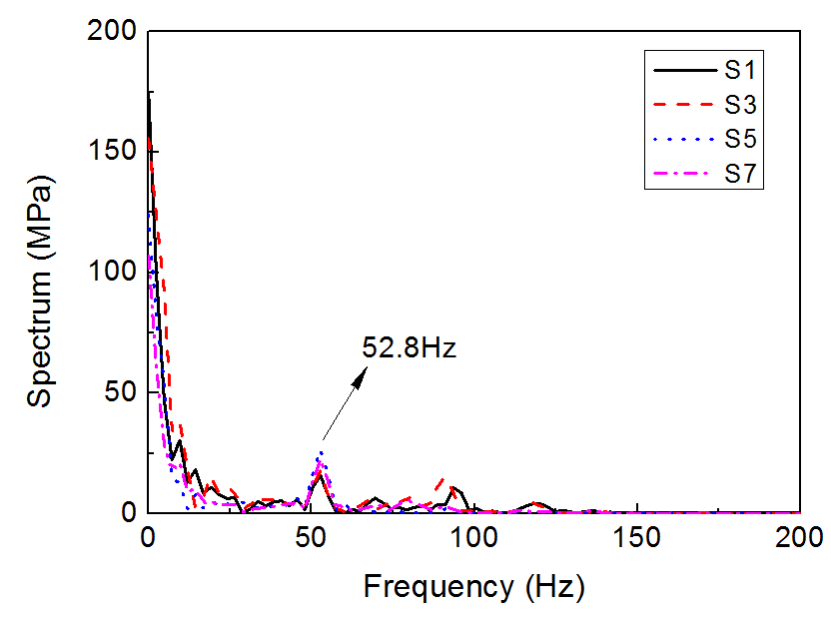

Figure 10. Fast Fourier transform (FFT) of the stress responses without the added mass.

Table 2. Comparison of peak values of absolute stresses.

\begin{tabular}{cccc}
\hline Positions & $\boldsymbol{\sigma}_{\text {we }}(\mathbf{M P a})$ & $\boldsymbol{\sigma}_{\text {woe }}(\mathbf{M P a})$ & $\boldsymbol{\sigma}_{\text {we }} / \boldsymbol{\sigma}_{\text {woe }} \mathbf{- 1}$ \\
\hline S1 & 349.12 & 290.94 & $20.00 \%$ \\
S2 & 464.76 & 446.3 & $4.14 \%$ \\
S3 & 439.55 & 426.27 & $3.12 \%$ \\
S4 & 74.184 & 72.59 & $2.20 \%$ \\
S5 & 256.11 & 242.95 & $5.42 \%$ \\
S6 & 193.54 & 185.86 & $4.13 \%$ \\
S7 & 274.3 & 188.18 & $45.76 \%$ \\
S8 & 285.48 & 273.12 & $4.53 \%$ \\
S9 & 282.5 & 267.11 & $5.76 \%$ \\
\hline
\end{tabular}

S1-S9: the locations on the stiffened plate for the analysis of structural stress responses.

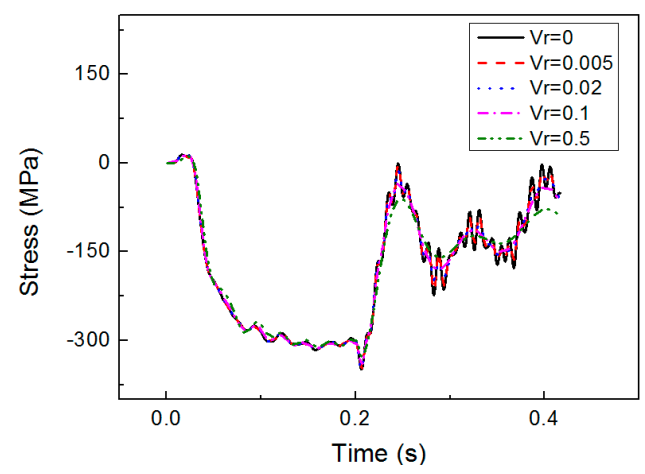

(a)

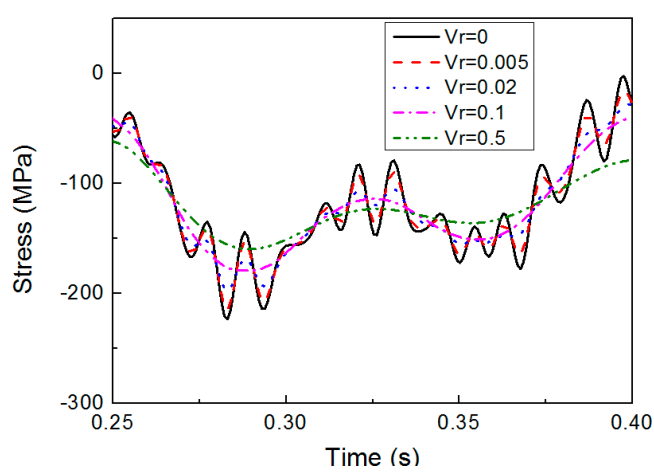

(b)

Figure 11. Cont. 


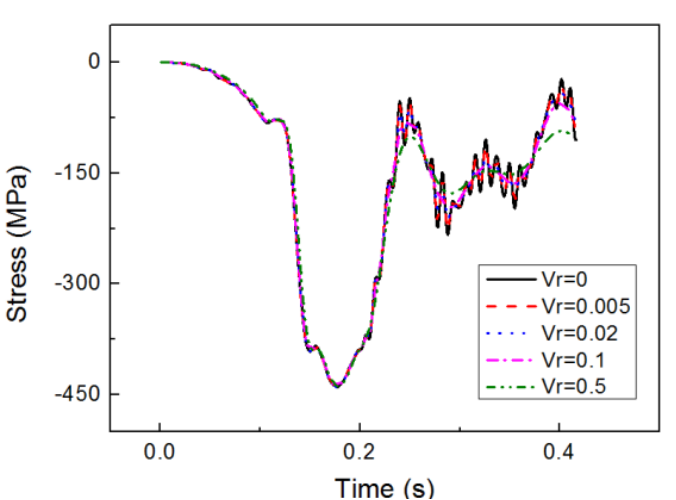

(c)

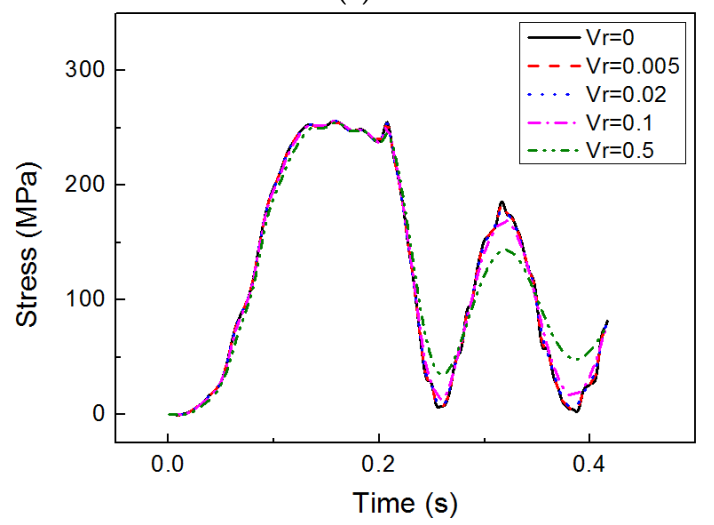

(e)

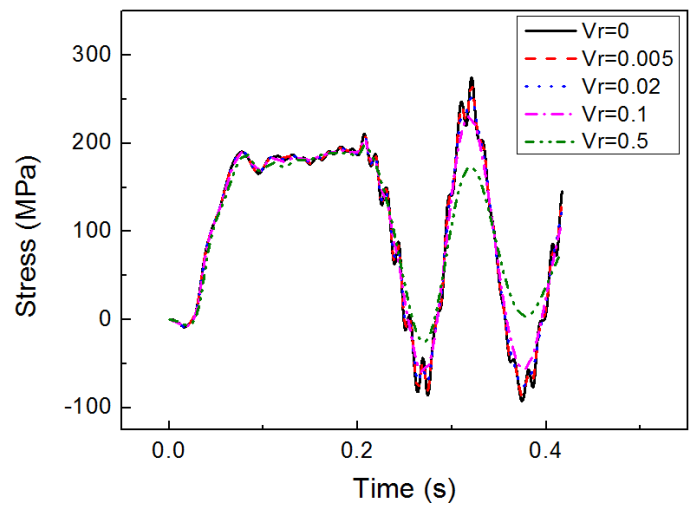

(g)

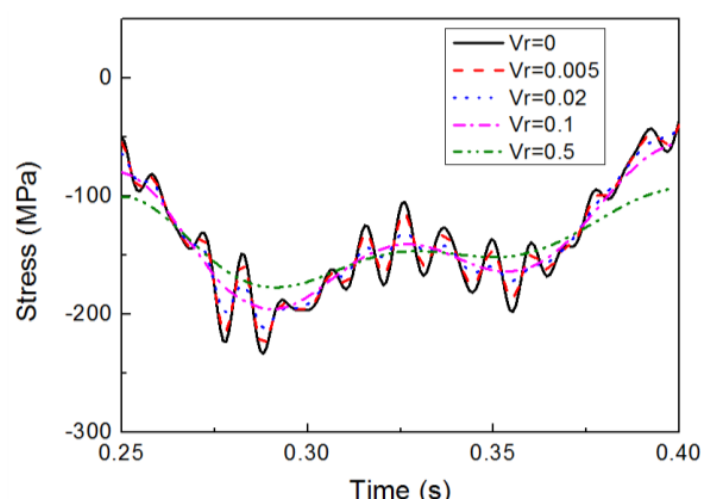

(d)

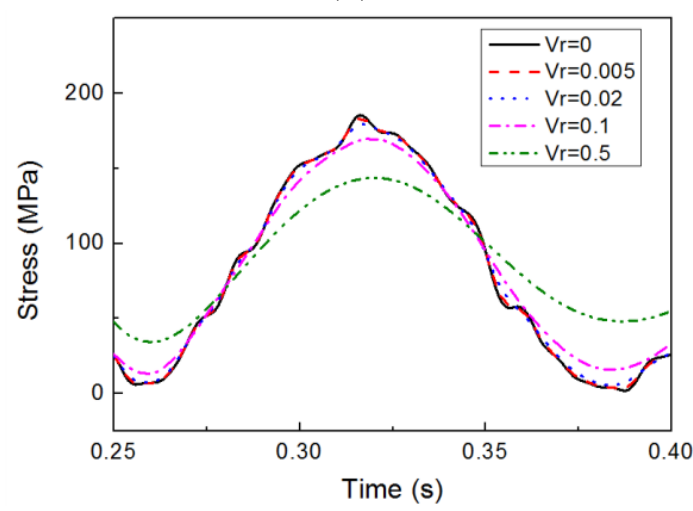

(f)

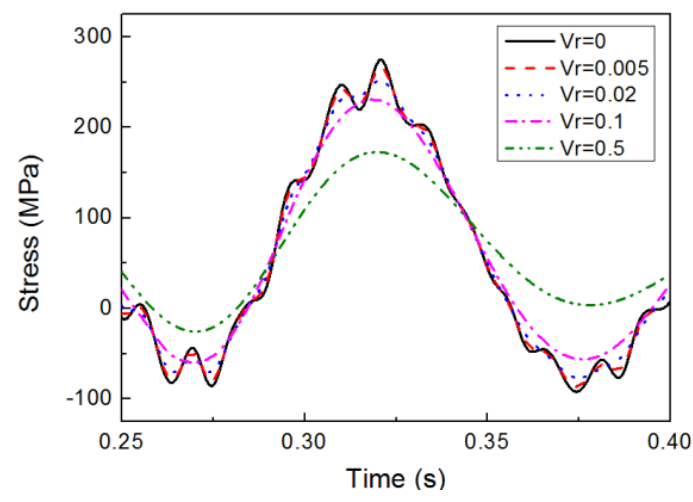

(h)

Figure 11. Comparative analysis on the effect of the structural damping. (a) entire simulation of S1; (b) vibration response of S1 after the flow separation; (c) entire simulation of S3; (d) vibration response of S3 after the flow separation; (e) entire simulation of S5; (f) vibration response of S5 after the flow separation ( $\mathrm{g}$ ) entire simulation of S7; (h) vibration response of S7 after the flow separation.

\section{Conclusions}

A dynamic model for calculating the response of a 3D wedge during the constant-velocity water entry has been presented. The structural dynamic equation is established by using the normal mode method. The impact load after the flow separation is obtained by applying a semi-analytical impact model. The added mass is expressed as generalized hydrodynamic coefficients, based on the potential theory. Effects of the added mass and the structural damping on the dynamic response of the wedge have been investigated.

Detailed validations of the present method have been conducted. The hydrodynamic impact load has been verified by making comparisons with the results of $2 \mathrm{D}$ rigid wedges in the published 
literatures. The effect of the added mass, including the stages before and after the flow separation, has been verified by comparing with the structural response of the 2D elastic wedge reported in the published literature. The applicability of the present method to 3D wedges has been verified by comparing with the results computed using the commercial software LS-DYNA.

Before flow separation, the added mass does not change the overall trend of the stress response. However, it can slightly increase the stress response. After the flow separation, the added mass can reduce the vibration frequency. For some positions, the stress response after the flow separation is even higher than that before the flow separation, due to the effect of the added mass.

The structural damping has a negligible effect on the stress before the flow separation within the structural damping factor range of the ship steel, while it can reduce the vibration stress after the flow separation.

Author Contributions: All three authors contributed equally to form the objectives of this paper and perform discussion of the numerical simulations and results. P.Y. performed the simulations, analyzed the data and wrote the paper under the supervision of M.C.O. and H.L. M.C.O. and H.L. commented and revised the paper.

Acknowledgments: The project was supported by the National Natural Science Foundation of China (51709030).

Conflicts of Interest: The authors declare no conflict of interest.

\section{Appendix A. The Semi-Analytical Model Based on the Modified Logvinovich Model}

The derivation of the semi-analytical model reported by Yu et al. [7] is shown in the following description. This model is based on the Modified Logvinovich model. The definition sketch of the impact model is illustrated in Figure 1. Note that, the meanings of symbols in this section are the same as that in Section 2.

For the Modified Logvinovich model [32], when the wedge section enters the fluid at a constant velocity, the distribution of pressure in the contact region is given as follows.

$$
P_{r}(x, t)=\frac{1}{2} \rho V^{2}\left[\frac{2 \dot{c}(t)}{V} \frac{c(t)}{\sqrt{c^{2}(t)-x^{2}}}-\cos ^{2} \beta \frac{c^{2}(t)}{c^{2}(t)-x^{2}}-\sin ^{2} \beta\right]
$$

$c(t)$ is determined with the help of the Wagner condition, which can be written as:

$$
\int_{0}^{\pi / 2} f[c(t) \sin \theta] d \theta=\frac{\pi}{2} V t
$$

where $f(x)$ is the function to describe the section shape. $\pi / 2$ on the right side of the equation is the fluid surface rise coefficient and it is denoted as $c_{v}$ in the following expressions. By comparing with results of the CFD method, $c_{v}$ was suggested to be 1.54 in Yu et al. [7].

In the case of the wedge, the Equation (A2) can be expressed in the form:

$$
c(t)=\frac{c_{v} V t}{\tan \beta}
$$

Influenced by $-\cos ^{2} \beta \frac{c^{2}}{c^{2}-x^{2}}$ in Equation (A1), the pressure of the contact region edge tends to be negative infinity. By assuming $P[a(t), t]=0$, the impact pressure $P(x, t)$ in the region $-a(t)<x<a(t)$ is positive. In order to solve the equation $P[a(t), t]=0$, it is convenient to define the ratio $\tau=a(t) / c(t)$ and $\tau=\sqrt{1-X^{2}}$. Then, we obtain

$$
X=\frac{\sin (2 \beta)}{2 c_{v}\left[1+\sqrt{1-c_{v}^{-2} \sin ^{4} \beta}\right]}
$$

It can be found that the value of $\tau$ decreases with the increase of the deadrise angle $\beta$, which means that the region of negation pressure increases. During the water entry of the rigid wedge section with 
a constant velocity, the pressure of the contact region should always be positive [4]. The pressure distribution of the region $-a(t)<x<a(t)$ is mapped to the region $-c(t)<x<c(t)$ by the ratio $\tau$ in order to correct the unreasonable negative pressure. Thus, the pressure distribution pressure in the contact region is given as:

$$
P_{r}(x, t)=\frac{1}{2} \rho V^{2}\left[\frac{2 \dot{c}}{V} \frac{c}{\sqrt{c^{2}-(\tau x)^{2}}}-\cos ^{2} \beta \frac{c^{2}}{c^{2}-(\tau x)^{2}}-\sin ^{2} \beta\right]
$$

It can be seen that the pressure is equal to zero when $x$ is equal to $c$, and the unreasonable negative pressure is avoided.

As shown in Figure 1b, a fictitious section is introduced to deal with the flow separation. On the assumption that the fluid rises along the fictitious section after flow separation, the section shape function considering the fictitious section is given as:

$$
f(x)=\left\{\begin{array}{lr}
x \tan \beta & 0 \leq x \leq L \cos \beta \\
b \tan \beta+(x-b) \tan \alpha & x>L \cos \beta
\end{array}\right.
$$

where $\alpha$ is the location angle of the fictitious section and it was suggested to be $40^{\circ}$ for wedges with $10^{\circ}$ and $20^{\circ}$ deadrise angles in Yu et al. [7].

By getting the time derivative of both sides of Equation (A2), we obtain

$$
\int_{0}^{\pi / 2} f_{x}[c(t) \sin \theta] \cdot \dot{c}(t) \cdot \sin \theta d \theta=c_{v} V
$$

where $f_{x}(x)$ is given as:

$$
f_{x}(x)=\left\{\begin{array}{rr}
\tan \beta & 0 \leq x \leq L \cos \beta \\
\tan \alpha & x>L \cos \beta
\end{array}\right.
$$

By introducing a parameter $\theta_{s}$ that satisfies the equation $c(t) \cdot \sin \theta_{s}=L \cos \beta$, Equation (A7) can be transformed into the following expression:

$$
\begin{gathered}
\dot{c}(t)\left\{\tan \beta \int_{0}^{\theta_{s}} \sin \theta d \theta+\tan \alpha \int_{\theta_{s}}^{\pi / 2} \sin \theta d \theta\right\}=c_{v} V \\
\dot{c}(t)=\frac{c_{v} V}{\tan \beta\left(1-\cos \theta_{s}\right)+\tan \alpha \cos \theta_{s}}
\end{gathered}
$$

In general, the expression of pressure distribution before and after flow separation is the same, and the difference is the calculation of $\dot{c}(t)$. Hence, the pressure distribution of the semi-analytical model can be expressed in the following equations.

$$
\begin{gathered}
P_{r}(x, t)=\frac{1}{2} \rho V^{2}\left[\frac{2 \dot{c}}{V} \frac{c}{\sqrt{c^{2}-(\tau x)^{2}}}-\cos ^{2} \beta \frac{c^{2}}{c^{2}-(\tau x)^{2}}-\sin ^{2} \beta\right] \\
\frac{d c}{d t}=\frac{c_{v} V}{\tan \beta} \text { before the flow separation } \\
\frac{d c}{d t}=\frac{c_{v} V}{\tan \beta\left(1-\cos \theta_{s}\right)+\tan \alpha \cos \theta_{s}} \text { after the flow separation }
\end{gathered}
$$

By comparing with the pressure distribution of the similarity solution, a pressure truncation is applied to the semi-analytical model reported by Yu et al. [7]. 


$$
P_{r}(x, t)=\min \left(P_{r}(x, t), \frac{1}{2} C_{P \max } \rho V^{2}\right)
$$

where $C_{P \max }$ is the peak coefficient for the impact pressure.

$$
C_{P \max }=\left(1.4763 \times 10^{-4} \beta^{2}-1.1551 \times 10^{-2} \beta+2.5243\right) / \tan ^{2} \beta
$$

where the unit of $\beta$ is degree.

\section{Appendix B. Modal Analysis}

Modal analysis of the stiffened plate is performed using the commercial software Nastran. The eigenvalues are calculated using the Lanczos method and the mass normalization method is adopted. Table A1 lists the natural frequency, general mass and general stiffness of the first 5 modes. Figure A1 shows the first 5 displacement modes of the stiffened panel. In fact, much more modes are adopted in the modal convergence study and their modal results are not all presented in this paper. The modal effective mass ratio of different first modes is shown in Figure A2. The modal mass ratio gradually increases with the increase of the number of modes.

\begin{tabular}{|c|c|c|c|}
\hline Order & Natural Frequency $(\mathrm{Hz})$ & General Mass $\left(\mathrm{kg} \cdot \mathrm{m}^{2}\right)$ & General Stiffness $\left(\mathrm{N} \cdot \mathrm{m} \times 10^{5}\right)$ \\
\hline 1 & 52.89 & 1.00 & 1.10 \\
\hline 2 & 61.18 & 1.00 & 1.48 \\
\hline 3 & 63.89 & 1.00 & 1.61 \\
\hline 4 & 65.69 & 1.00 & 1.70 \\
\hline 5 & 66.32 & 1.00 & 1.74 \\
\hline
\end{tabular}

Table A1. Natural frequency, general mass and general stiffness.

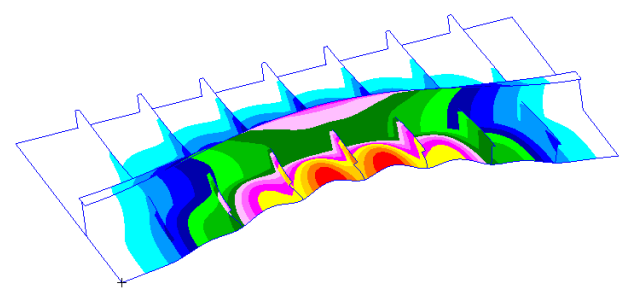

(a)

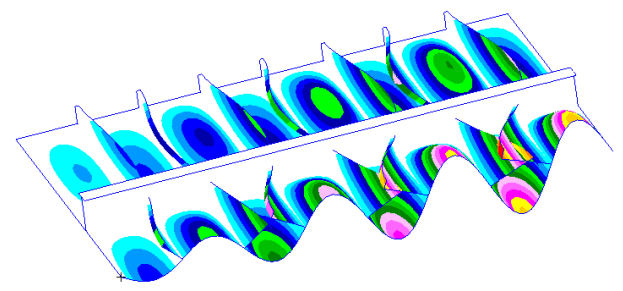

(c)

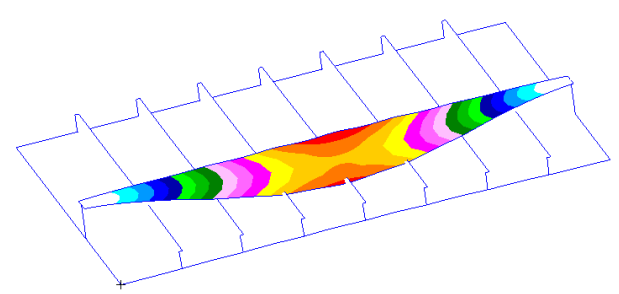

(b)

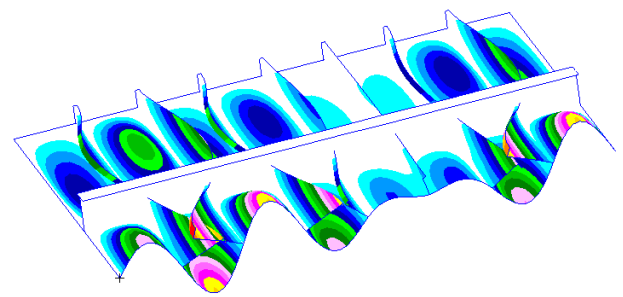

(d)

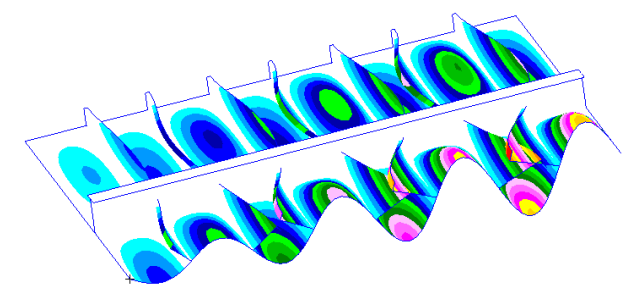

(e)

Figure A1. Displacement modes of the stiffened panel. (a) The first order; (b) The second order; (c) The third order; (d) The fourth order; (e) The fifth order. 


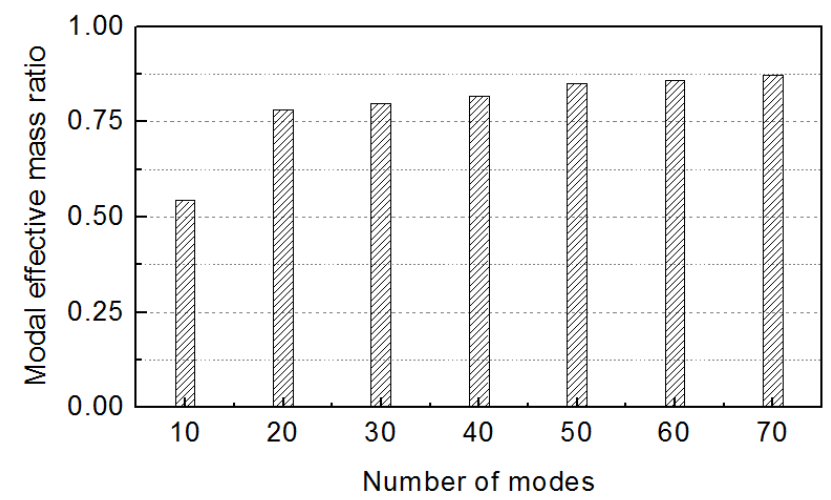

Figure A2. Modal mass ratio of different first modes.

\section{Appendix C. Modal Convergence Study}

Figure A3 shows the comparison of the impact dynamic response with different number of modes. The impact velocity is constantly set as $6 \mathrm{~m} / \mathrm{s}$. It can be seen that the stress responses of each position tends to converge with the increase of the number of modes. The stress responses of the first 50,60 and 70 modes are close to each other. The normal mode method is essentially an approximate method due to the truncation of the number of modes. More modes will provide more accurate results; however, it will consume more time. Even if there are still some slight discrepancies, it is considered that the first 50 modes are sufficient to calculate the structural response of the elastic wedge during the water entry.

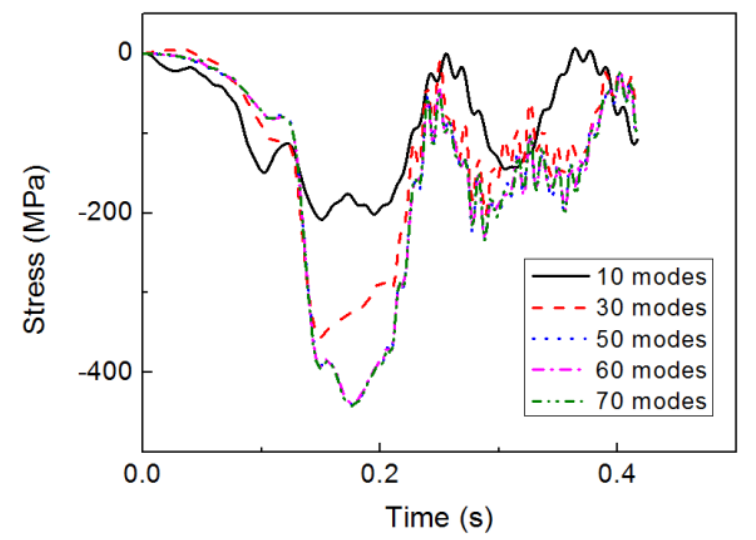

(a)

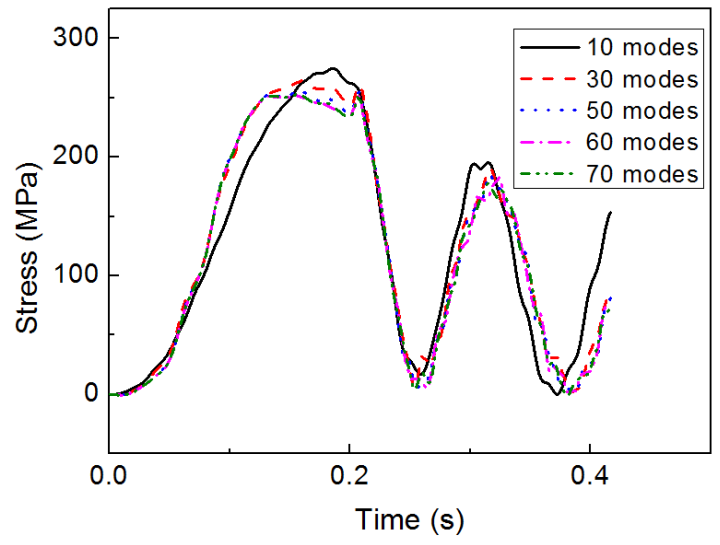

(c)

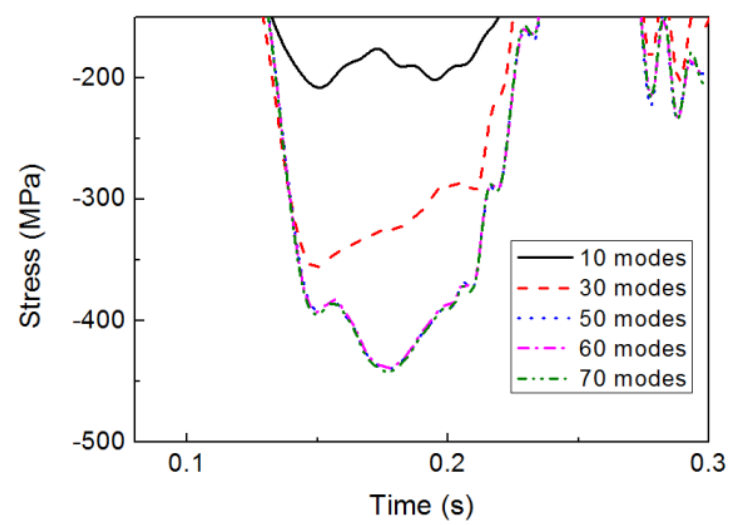

(b)

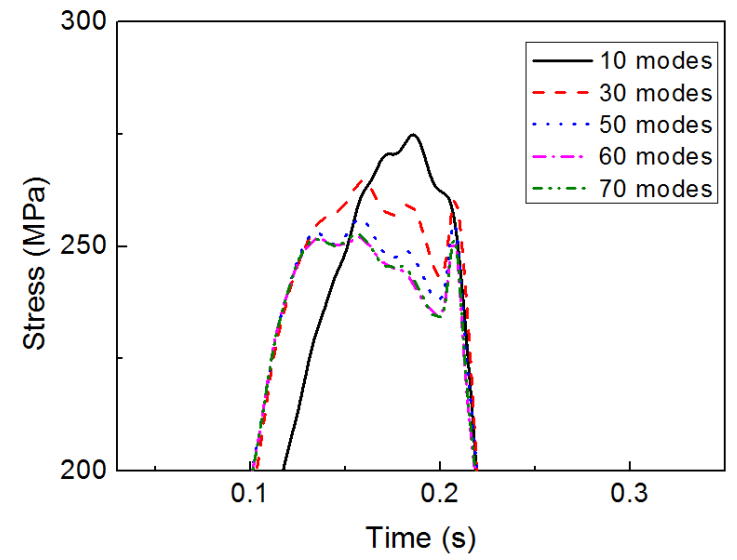

(d)

Figure A3. Cont. 


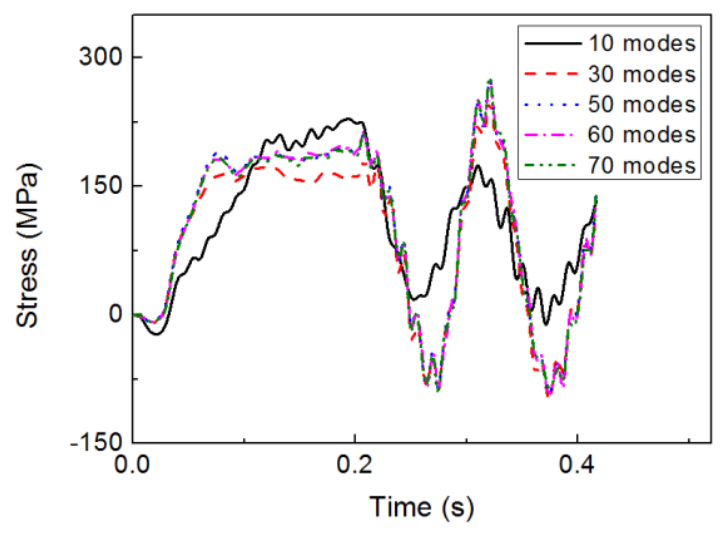

(e)

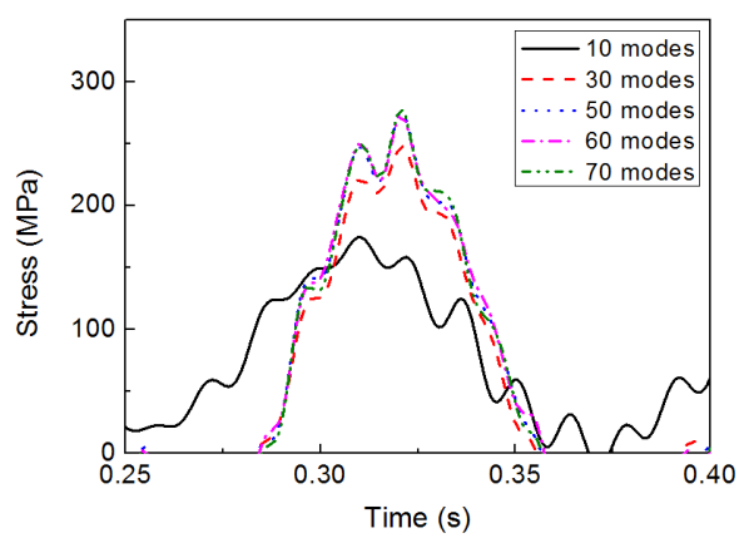

(f)

Figure A3. Dynamic response with different number of modes. (a) entire simulation of S3; (b) near the maximum stress of S3; (c) entire simulation of S5; (d) near the maximum stress of S5; (e) entire simulation of $\mathrm{S7}$; (f) near the maximum stress of S7.

\section{References}

1. Xu, G.D.; Duan, W.Y.; Wu, G.X. Numerical simulation of oblique water entry of an asymmetrical wedge. Ocean Eng. 2008, 35, 1597-1603. [CrossRef]

2. Von Karman, T. The Impact on Seaplane Floats during Landing; Technical Report Archive \& Image Library; NTRS: Washington, DC, USA, 1929.

3. Wagner, H. Uber Stoss- und Gleitvorgange an der Oberflache von Flussigkeiten. ZAMM J. Appl. Math. Mech. 1932, 12, 193-215. [CrossRef]

4. Zhao, R.; Faltinsen, O. Water entry of two-dimensional bodies. J. Fluid Mech. 1993, 246, 593-612. [CrossRef]

5. Tassin, A.; Jacques, N.; El Malki Alaoui, A.; Nême, A.; Leblé, B. Assessment and comparison of several analytical models of water impact. Int. J. Multiphys. 2010, 4, 125-140. [CrossRef]

6. Tassin, A.; Korobkin, A.A.; Cooker, M.J. On analytical models of vertical water entry of a symmetric body with separation and cavity initiation. Appl. Ocean Res. 2014, 48, 33-41. [CrossRef]

7. Yu, P.Y.; Ren, H.L.; Li, H.; Wang, S.; Sun, L.M. Slamming study of wedge and bow-flared sections. J. Ship Mech. 2016, 20, 1109-1120. [CrossRef]

8. Wang, J.; Lugni, C.; Faltinsen, O.M. Experimental and numerical investigation of a freefall wedge vertically entering the water surface. Appl. Ocean Res. 2015, 51, 181-203. [CrossRef]

9. Bao, C.M.; Wu, G.X.; Xu, G. Simulation of freefall water entry of a finite wedge with flow detachment. Appl. Ocean Res. 2017, 65, 262-278. [CrossRef]

10. Kamath, A.; Bihs, H.; Arntsen, O.A. Study of water impact and entry of a free falling wedge using computational fluid dynamics simulations. J. Offshore Mech. Arct. Eng. 2017, 139. [CrossRef]

11. Yettou, E.-M.; Desrochers, A.; Champoux, Y. Experimental study on the water impact of a symmetrical wedge. Fluid Dyn. Res. 2006, 38, 47-66. [CrossRef]

12. Jalalisendi, M.; Shams, A.; Panciroli, R.; Porfiri, M. Experimental reconstruction of 3D hydrodynamic loading in water entry problems through particle image velocimetry. Exp. Fluids 2015, 56, 41. [CrossRef]

13. Jalalisendi, M.; Porfiri, M. Water entry of compliant slender bodies: Theory and experiments. Int. J. Mech. Sci. 2017. [CrossRef]

14. Korobkin, A.; Gueret, R.; Malenica, S. Hydroelastic coupling of beam finite element model with Wagner theory of water impact. J. Fluids Struct. 2006, 22, 493-504. [CrossRef]

15. Qin, Z.; Batra, R.C. Local slamming impact of sandwich composite hulls. Int. J. Solids Struct. 2009, 46, 2011-2035. [CrossRef]

16. Khabakhpasheva, T.I.; Korobkin, A.A. Elastic wedge impact onto a liquid surface: Wagner's solution and approximate models. J. Fluids Struct. 2013, 36, 32-49. [CrossRef]

17. Datta, N.; Siddiqui, M.A. Hydroelastic analysis of axially loaded Timoshenko beams with intermediate end fixities under hydrodynamic slamming loads. Ocean Eng. 2016, 127, 124-134. [CrossRef] 
18. Shams, A.; Porfiri, M. Treatment of hydroelastic impact of flexible wedges. J. Fluids Struct. 2015, 57, $229-246$. [CrossRef]

19. Shams, A.; Zhao, S.; Porfiri, M. Hydroelastic slamming of flexible wedges: Modeling and experiments from water entry to exit. Phys. Fluids 2017, 29. [CrossRef]

20. Lu, C.H.; He, Y.S.; Wu, J.X. Coupled analysis of nonlinear interaction between fluid and structure during impact. J. Fluids Struct. 2000, 14, 127-146. [CrossRef]

21. Maki, K.J.; Lee, D.; Troesch, A.W.; Vlahopoulos, N. Hydroelastic impact of a wedge-shaped body. Ocean Eng. 2011, 38, 621-629. [CrossRef]

22. Piro, D.J.; Maki, K.J. Hydroelastic analysis of bodies that enter and exit water. J. Fluids Struct. 2013, 37, 134-150. [CrossRef]

23. Panciroli, R. Dynamic Failure of Composite and Sandwich Structures. In Solid Mechanics and Its Applications; Abrate, S., Castanié, B., Rajapakse, Y., Eds.; Springer: Dordrech, The Netherlands, 2013; Volume 192, pp. 1-45. ISBN 978-94-007-5328-0.

24. Panciroli, R.; Abrate, S.; Minak, G. Dynamic response of flexible wedges entering the water. Compos. Struct. 2013, 99, 163-171. [CrossRef]

25. Das, K.; Batra, R.C. Local water slamming impact on sandwich composite hulls. J. Fluids Struct. 2011, 27, 523-551. [CrossRef]

26. Stenius, I.; Rosén, A.; Kuttenkeuler, J. Hydroelastic interaction in panel-water impacts of high-speed craft. Ocean Eng. 2011, 38, 371-381. [CrossRef]

27. Faltinsen, O.M. Water entry of a wedge by hydroelastic orthotropic plate theory. J. Ship Res. 1999, 43, 180-193.

28. Luo, H.; Wang, H.; Guedes Soares, C. Numerical and experimental study of hydrodynamic impact and elastic response of one free-drop wedge with stiffened panels. Ocean Eng. 2012, 40, 1-14. [CrossRef]

29. Luo, H.; Wang, H.; Guedes Soares, C. Comparative study of hydroelastic impact for one free-drop wedge with stiffened panels by experimental and explicit finite element methods. In Proceedings of the ASME 2011 30th International Conference on Ocean, Offshore and Arctic Engineering, Rotterdam, The Netherlands, 19-24 June 2011. [CrossRef]

30. China Classification Society (CCS). Rules for Construction and Classification of Sea-Going High Speed Craft; China Classification Society: Beijing, China, 2012; pp. 50-57.

31. Wu, M.; Moan, T. Sensitivity of extreme hydroelastic load effects to changes in ship hull stiffness and structural damping. Ocean Eng. 2007, 34, 1745-1756. [CrossRef]

32. Korobkin, A. Analytical models of water impact. Eur. J. Appl. Math. 2004, 15, 821-838. [CrossRef] 